\title{
Projections of global warming-induced impacts on winter storm losses in the German private household sector
}

\author{
Hermann Held · Friedrich-Wilhelm Gerstengarbe • Tobias Pardowitz • \\ Joaquim G. Pinto • Uwe Ulbrich • Kai Born • Markus G. Donat • \\ Melanie K. Karremann • Gregor C. Leckebusch • Patrick Ludwig • \\ Katrin M. Nissen · Hermann Österle • Boris F. Prahl • Peter C. Werner • \\ Daniel J. Befort • Olaf Burghoff
}

Received: 31 January 2013 / Accepted: 15 August 2013 / Published online: 18 September 2013

(C) The Author(s) 2013. This article is published with open access at Springerlink.com

\begin{abstract}
We present projections of winter storm-induced insured losses in the German residential building sector for the 21st century. With this aim, two structurally most independent downscaling methods and one hybrid downscaling method are applied to a 3-member ensemble of ECHAM5/MPI-OM1 A1B scenario simulations. One method uses dynamical downscaling of intense winter storm events in
\end{abstract}

Electronic supplementary material The online version of this article (doi:10.1007/s10584-013-0872-7) contains supplementary material, which is available to authorized users.

H. Held $(\varangle)$

Department of Geosciences and Department of Economics,

University of Hamburg-KlimaCampus, Grindelberg 5, 20144 Hamburg, Germany

e-mail: hermann.held@zmaw.de

H. Held · F. W. Gerstengarbe · H. Österle · B. F. Prahl · P. C. Werner

Potsdam Institute for Climate Impact Research, Potsdam, Germany

T. Pardowitz · U. Ulbrich · K. M. Nissen · D. J. Befort

Institute of Meteorology, Freie Universität Berlin, Berlin, Germany

J. G. Pinto · K. Born · M. K. Karremann · P. Ludwig

Institute for Geophysics and Meteorology, University of Cologne, Cologne, Germany

J. G. Pinto

Department of Meteorology, University of Reading, Reading, UK

M. G. Donat

Climate Change Research Centre, University of New South Wales, Sydney, Australia

G. C. Leckebusch

School of Geography, Earth and Environmental Sciences, University of Birmingham, Birmingham, UK

O. Burghoff

German Insurance Association (GDV), Berlin, Germany 
the global model, and a transfer function to relate regional wind speeds to losses. The second method is based on a reshuffling of present day weather situations and sequences taking into account the change of their frequencies according to the linear temperature trends of the global runs. The third method uses statisticaldynamical downscaling, considering frequency changes of the occurrence of storm-prone weather patterns, and translation into loss by using empirical statistical distributions. The A1B scenario ensemble was downscaled by all three methods until 2070, and by the (statistical-) dynamical methods until 2100. Furthermore, all methods assume a constant statistical relationship between meteorology and insured losses and no developments other than climate change, such as in constructions or claims management. The study utilizes data provided by the German Insurance Association encompassing 24 years and with district-scale resolution. Compared to 1971-2000, the downscaling methods indicate an increase of 10-year return values (i.e. loss ratios per return period) of 6-35\% for 2011-2040, of 20-30\% for 20412070 , and of 40-55 \% for 2071-2100, respectively. Convolving various sources of uncertainty in one confidence statement (data-, loss model-, storm realization-, and Pareto fit-uncertainty), the return-level confidence interval for a return period of 15 years expands by more than a factor of two. Finally, we suggest how practitioners can deal with alternative scenarios or possible natural excursions of observed losses.

\section{Introduction}

Winter storms represent one of the major natural hazards. Based on three decades of data (1982-2011) from the EM-DAT ${ }^{1}$ database (e.g. Guha-Sapir et al. 2012) extratropical storms account for a world-wide average of annual economic loss of USD 10.7 bn in 2011 prices. According to Kron et al. (2012), the cumulative world-wide losses 1980-2012 amount for USD 178 bn (2012 prices). For Europe, current estimates for a single 10-year event reach USD 7 bn (2006 prices), increasing up to USD 30 bn for events with a return level of once per 100 years (Schwierz et al. 2010). Changes in winter storm statistics related to global warming have been studied in several investigations, in particular referring to the Euro-Atlantic area (e.g. Ulbrich et al. 2009). Additionally, several studies indicate that losses from winter storms may increase in future decades over Western Europe (e.g. Donat et al. 2011a; Leckebusch et al. 2007; Pinto et al. 2012; Schwierz et al. 2010). Hence, winter storms clearly have the potential for a relevant global warming impact category. Further, the international debate on an adequate climate policy is shifting from a mitigation-oriented focus towards a broader perspective including more of the impact and adaptation side. ${ }^{2}$ With this aim, we suggest a new methodological

\footnotetext{
${ }^{1}$ EM-DAT: The OFDA/CRED International Disaster Database-www.emdat.net-Université catholique de Louvain-Brussels-Belgium.

${ }^{2}$ To illustrate, the desire to represent the impacts of global warming in a more explicit and accurate manner recently led to the launch of the impact model intercomparison activity ISI-MIP (Schiermeier 2012).
} 
approach for combining different impact assessment techniques and integrating the related measures of uncertainty. We suggest that the sequence demonstrated here for the special case of storm losses in Germany will be relevant for impact modeling in general.

Losses caused by European winter storms are particularly relevant for western and central European countries (e.g. Della-Marta and Pinto 2009; Haylock 2011; Leckebusch et al. 2007). Average annual storm-related insured losses to residential buildings in Germany add up to about EUR 1.1 bn (GDV 2012). The link between extreme wind speeds and induced insured losses is dependent on the spatial distribution of winter storm (hazard) intensities and the vulnerabilities of local buildings (e.g. Donat et al. 2011b; Prahl et al. 2012). As there is no unique mechanism quantifying the vulnerabilities which may differ between regions, the assessment of any 'winter storm intensity-loss'-relation must rely on statistical data. In that regard, insurance companies hold the most reliable and systematic records. Annual values of insured losses for Germany had been used in previous works (e.g. Leckebusch et al. 2007; Pinto et al. 2007). For the first time, the German Insurance Association (Gesamtverband der Deutschen Versicherungswirtschaft e.V., GDV) provided highly spatio-temporally resolved data on storm and hail losses from the German residential building sector for a scientific project. Currently, about $93 \%$ of private buildings in Germany are insured. For that reason, we assume that the results derived from that dataset are representative for the sector as a whole.

In this article we provide a compilation of results from the project focusing on global-warming induced changes of winter storm losses over Germany based on ensemble projections with one coupled global climate model (GCM). At the same time, the subsequent methodological advancements are highlighted. The key sources of uncertainty are estimated in a causal chain from global warming projections to economic losses including the step of regionalization. We utilize three different approaches to regionalization of winter storms. As these approaches produce different results by applying different methodologies to one common driver (ECHAM5/MPIOM1 GCM scenario runs), they constitute a 3-model ensemble in some sense. Basically, the three approaches correspond to dynamical downscaling, statistical downscaling, and a hybrid of dynamical and statistical downscaling. Firstly, the applied methods are described in more detail in the following Section, and specific results are given in Section 3. Secondly, we attempt a semi-quantitative discussion of all major uncertainties and, to a large extent, their synergetic effects along the causal chain, as outlined in Section 4. Thirdly, the uncertainties are evaluated based on both academic and stakeholder insurance industry standards. The implications of the latter are further incorporated into the summary in Section 5.

\section{Data base and modeling approaches}

For this study the GDV provided loss records on a daily basis, distinguished for the 439 administrative districts of Germany (status of 2006 for homogeneity reasons). The datasets are described in Donat et al. (2011b). Loss amounts are considered by using loss ratios, i.e. the ratio between claims and insured values (unit: EUR per EUR 1000 , i.e. in \%o). The loss data contain information on damage to residential buildings (line of business 'comprehensive insurance on buildings', in German 'Verbundene 
Wohngebäude Versicherung') caused by storm or hail, and consist of three separate datasets:

- daily loss values per district 1997-2007

- annual loss and portfolio values per district 1981-2007

- daily loss values per district 1984-2008 of a simulation of residential buildings losses from losses due to storm/hail/lightning in motor own damage insurance.

All methods use various reanalysis datasets for the representation of the current climate, namely NCEP/NCAR (Kalnay et al. 1996), ERA-40 (Uppala et al. 2005), and ERA-Interim (Dee et al. 2011). A 3-member ensemble ${ }^{3}$ of climate change experiments performed with the atmosphere-ocean coupled ECHAM5/MPI-OM1 (hereafter ECHAM5; Jungclaus et al. 2006) following the 20C (1860-2000) and the SRES A1B scenarios (2001-2100; Nakicenovic and Swart 2000) is used in this study. We focus on the period 1971-2000 for recent climate conditions, and for 2011-2040, 2041-2070, and 2071-2100 for future climate conditions.

For the dynamical downscaling (DD) approach, the storm events in Germany are identified using an impact model for storm damages (e.g. Klawa and Ulbrich 2003; Leckebusch et al. 2007; Pinto et al. 2007). The model translates wind speeds into loss, assuming that loss is induced when wind speeds exceed a minimum value, which is associated with the 98th percentile of local wind climate. Thus, a regional adaptation is assumed. Loss is increasing with the third power of normalized excess over this threshold. The storm loss model is calibrated with Reanalysis data and loss data from the GDV at the district scale (Donat et al. 2011b). Climate models produce their own wind climatologies, with inherent biases against observational data. Loss associated with the models' windstorms can, however, be estimated using the respective 98th percentile and normalized excess of storm wind speeds rather than their absolute values. For simulations of historical storms, the regional climate model COSMOCLM (Rockel et al. 2008) with an implemented wind gust parameterization (see Born et al. 2012, for validation and more details) is used. Synthetic storms identified in the global model for recent and future climate conditions are also dynamically downscaled by the same RCM. In order to estimate uncertainties, 5 RCM ensemble runs are produced for each storm by shifting the spatial domain of the nesting region by 8 grid points (see Supplementary Material). This shift is resulting in equally valid developments of a storm, as there is no preferred predefined position of the nesting region. This should be distinguished from ensemble forecast generations, which aim to estimate the effects of variations in physics and in modifying the initial conditions with specific anomalies. For each simulation, the storm loss model is applied for making loss data available. This method will thus sample for the uncertainty of a specific storm situation from its dynamical aspects: Given the same forcing conditions, a different realization might exist and the real event is only one of multiple possible realizations. Further details can be found in the Electronic Supplemental Material, Section 1.

Statistical downscaling (SD) is performed by the statistical regional climate model STARS (STatistical Analog Resampling Scheme; Orlowsky et al. 2008). It

\footnotetext{
${ }^{3}$ Representing different initial conditions.
} 
calculates regional climate projections of daily meteorological variables for the next few decades. The model uses historical observations from weather stations and a prescribed future trend of a meteorological variable (in this case the annual mean of the air temperature, spatially distributed in the area of interest, here for Germany) in order to assemble a new meteorological data set that fulfills the trend prescription. Observed meteorological data associated with the trend variable are maintained, so temporal and spatial consistency in the future data set is assured. Because of the very modest demands in computational resources, the STARS model is able to simulate a large number of such data reassemblies, called realizations, for a given future trend of a meteorological variable.

The results of the global climate model ECHAM5 runs under scenario A1B forcing showed an average increase in temperatures of approximately $2.1 \mathrm{~K}$ has to be anticipated between 2011 and 2070. (This time period was selected because of the rule that the simulation period must not be longer than the observational period (Orlowsky et al. 2008).) However, spatially resolved temperature increases may differ from the average trend and were used as input for STARS. 1,000 realizations were generated. Using two further statistical methods (regression approach and analogue approach-for more information see Electronic Supplemental Material, Section 1) it was possible to estimate the future development of the loss ratios for winter storms based on the results of model STARS and the insurance data (Gerstengarbe et al. 2013).

The statistical-dynamical downscaling (SDD) method presents an alternative to purely dynamical or statistical approaches to determine the regional responses to climate change. SDD relies on regional modeling, on changes in frequencies of weather types, and on estimated statistical distributions of climate variables like wind (Fuentes and Heimann 2000; Pinto et al. 2010). The study uses NCEP/NCAR Reanalysis for the representation of storm-relevant weather classes following Leckebusch et al. (2008) under recent climate conditions (see Electronic Supplemental Material). In order to include the climate change signal, changes in the frequencies of weather classes between recent and future climate conditions as represented by ECHAM5 runs are considered. For storm-relevant weather classes, CCLM simulations of historical storms (Born et al. 2012) are conducted and considered as the dynamical part of this downscaling technique. The GDV loss data is used to calibrate a wind-loss relation in a parameter-free probabilistic relation using quantile regression. Unlike the dynamical approach, no RCM simulations for GCM storms are considered. Hence, the climate change signal is derived only from changes in the frequency of the storm-relevant weather classes and does not consider possible changes of intensity of singular events within a specific weather class. Further details can be found in the Electronic Supplemental Material.

Economic losses in the insurance sector are to a large extent influenced by extreme events that would appear at least once over the observational or projected period. Hence, the impact projections cannot be evaluated directly, but have to be extrapolated for less frequent events of even higher impact. We follow a standard approach, exploit the asymptotics of our extreme value statistic, and fit a Generalized Pareto Distribution (GPD, e.g. Coles 2001) to annual loss data (Donat et al. 2011b) of any 30-year period. Any GPD is characterized by three fit parameters that we determine as a maximum likelihood combination. Confidence intervals for $95 \%$ confidence levels are derived from the profile likelihoods following Coles (2001). 


\section{Results}

The results for all three methodologies regarding changes of return levels for selected return periods are summarized in Table 1. For DD and SDD, results are derived from all three ECHAM5 ensemble members and then pooled per period. For SD, the ensemble member is used as the driving input that is characterized by the median temperature trend (of the three), the latter not being significantly different from the ensembles mean trend (i.e. a change of $2.1 \mathrm{~K}$ for the period 2011 to 2070). Overall we observe an increase of return levels with time. We attribute the intermittent flips in sign to climate variability.

We display a characteristic extract from this in Fig. 1. For a given 'return period $T$ ' the so called 'return level' is that loss ratio, which would occur after an average waiting time $T$ due to an event of that magnitude or larger. As an example, Fig. 1 shows the changes of the return level (left) and the return period (right) for a loss corresponding to a 10 years event under recent climate conditions. The 10 years return level was chosen for Fig. 1 as this represents a return level were the upper end of the 'multiple-uncertainty' confidence interval (see next Section) is still a factor two (and not more) of the maximum likelihood level. Hence for larger return periods we regard the results as less robust. The right graph shows the return period of a loss that would have been a 10 years loss in the period 1971-2000. The according numbers are displayed in the Electronic Supplemental Material, Table 2.

Results indicate slightly higher return levels and shorter return periods of extreme losses under enhanced greenhouse gas conditions. However the observed changes are much smaller than the widths of most of the $95 \%$ confidence intervals. (A confidence level of $95 \%$ is often requested by practitioners.) Compared to 19712000 , the return levels for a 10 year event increase by 6-35\% for 2011-2040, by 20-30\% for 2041-2070, and by 40-55 \% for 2071-2100, respectively (cf. Table 1). Accordingly, the return period estimates for a 10 year return level are shortened, corresponding for example to 5.8-8.7 years for 2011-2040 (cf. right graph in Fig. 1 and Table 1 in the Electronic Supplemental Material). Concerning less frequent events, changes of return levels are of similar or larger order of magnitude as for a 10-year event: For example, the return level of a 25 -year event may increase by $5-41 \%$ and

Table 1 Return levels of economic losses for given return periods

\begin{tabular}{llllll}
\hline \multicolumn{2}{l}{ Return values in \%o for various return periods } & & \\
\hline Return period & Method & $1971-2000$ & $2011-2040$ & $2041-2070$ & $2071-2100$ \\
\hline 10 -year & SD & 0,18 & $0,19(+6 \%)$ & $0,23(+28 \%)$ & - \\
& DD & 0,20 & $0,27(+35 \%)$ & $0,24(+20 \%)$ & $0,31(+55 \%)$ \\
& SDD & 0,20 & $0,24(+20 \%)$ & $0,26(+30 \%)$ & $0,28(+40 \%)$ \\
25 -year & SD & 0,29 & $0,26(-10 \%)$ & $0,34(+17 \%)$ & - \\
& DD & 0,38 & $0,48(+26 \%)$ & $0,40(+5 \%)$ & $0,60(+58 \%)$ \\
50 -year & SDD & 0,22 & $0,26(+18 \%)$ & $0,31(+41 \%)$ & $0,32(+45 \%)$ \\
& SD & 0,39 & $0,30(-23 \%)$ & $0,43(+10 \%)$ & - \\
100 -year & DD & 0,53 & $0,63(+19 \%)$ & $0,49(-8 \%)$ & $0,82(+55 \%)$ \\
& SDD & 0,22 & $0,27(+23 \%)$ & $0,33(+50 \%)$ & $0,33(+50 \%)$ \\
& SD & 0,52 & $0,34(-35 \%)$ & $0,54(+4 \%)$ & - \\
& DD & 0,70 & $0,78(+11 \%)$ & $0,57(-19 \%)$ & $1,05(+50 \%)$ \\
& SDD & 0,23 & $0,27(+17 \%)$ & $0,33(+43 \%)$ & $0,33(+43 \%)$ \\
\hline
\end{tabular}



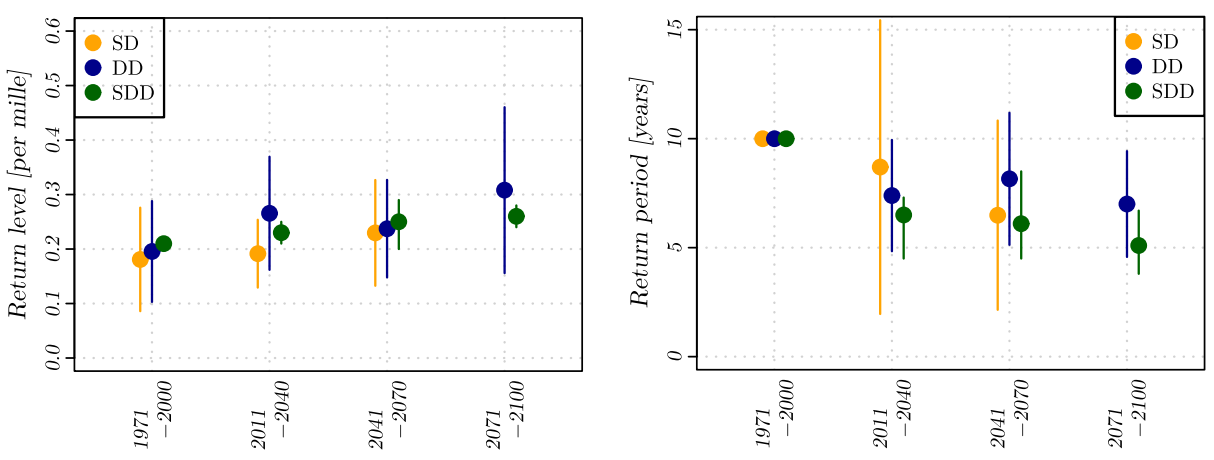

Fig. 1 Left projected return level of a once-in-10-years loss; right return period of a loss that would have been a 10 years loss in the period 1971-2000 (maximum likelihood values and $95 \%$ confidence intervals from profile likelihood method)

45-58 \% for the periods 2041-2070, and 2071-2100, respectively (Table 1). Note that the increase is not in all cases steady between the periods, and even changes of opposite sign are found for specific methods and periods. This fact is related to the presence of long term (decadal) climate variability superposed to the greenhouse gas signal: as single model simulations represent individual developments of (model-) climate, the respective return values will be strongly affected by such long-term variations. This is particularly relevant for the DD method (c.f. Section 4).

The confidence intervals of all three methods overlap in their projections. This is remarkable in the sense that the three methods are structurally very different. While the dynamical method is able to consider changes in intensity of storms under future climate conditions, the statistical method represents an optimal temperaturedriven extrapolation of observational weather patterns, and the statistical-dynamical method considers changes of storm-prone weather types. In fact, maximum storm losses for current climate conditions are exceeded under future climate conditions, particularly in the last decades of the 21st century (Pinto et al. 2012, their Fig. 4d).

Overall the results show a modest increase in return levels and shorter return periods due to global warming for Germany. This result, for the first time derived from a district-scale data set on insured losses, is in line with projected changes in extreme cyclones affecting Western Europe (Della-Marta and Pinto 2009; Donat et al. 2010), and with changes of return periods of estimated losses for Germany and nearby countries under several SRES scenarios (Donat et al. 2011a; Pinto et al. 2012).

\section{Uncertainty discussion along the causal chain}

Concerning the impacts of global warming on the private building sector, insurers as well as clients face the following main sources of uncertainty:

1. Uncertain future emission regulation and the subsequent emissions and concentration

2. Uncertain response of the global climate dynamics on greenhouse gas emissions 
3. Initial value problem: is the present-day 30 years window representative in terms of its extreme value statistics — or is it rather an excursion from the mean climate? Are the other periods representative for the respective GHG forcing?

4. Uncertainty in downscaling

5. Uncertainty in statistical relation from the meteorological phenomenon to the economic loss

6. Uncertainty in estimate of generalized Pareto distribution due to finite length of time series.

What could be the consequences of these sources of uncertainty for the interpretation of our results?

In addressing the first two items we clearly have to state that we present results only for the intermediate no-mitigation policy A1B scenario and only for ECHAM5 which is characterized by somewhat 'centered' response characteristics compared to other GCMs (with respect to the mean climate change signal of the storm track, please compare Ulbrich et al. 2008). Note, however, that beyond the mean climate response to rising greenhouse gas concentrations decadal climate variations are produced, see item \#3.

Here we offer one possible extrapolation of our results that might serve as a bridge as long as analyzes with other global scenarios are missing. The A1FI-SRES scenario represents the most aggressive of the SRES marker scenarios. When augmenting this scenario with climate response uncertainty, IPCC-AR4, WG-I, states a maximum warming of $6^{\circ} \mathrm{C}$ in the course of this century (Fig. 5, Summary for Policymakers; upper end of $90 \%$ quantile). In view of likely negative feedbacks of global warming (Stern 2007) on economic growth, we regard any warming beyond $6^{\circ} \mathrm{C}$ by 2100 as highly unlikely. Within the framework of our purely statistical approach STARS, climate evolution is seen as driven by the average temperature evolution. From that point of view, an A1FI scenario could be interpreted as an accelerated A1B scenario, from 2050 onwards, when scenarios start to diverge. In case one was willing to extrapolate that reasoning also to the results derived by our other two methods, this would imply that the warming-induced impacts could occur up to 15 years earlier than projected under the A1B scenario.

While standard impact publications based on GCM-warming scenarios generically project ratios of impacts from present-day to future time periods (as we do in our dynamical and our statistical-dynamical approach), real-world stakeholders are more interested in the ratio as induced by real future vs. real present climate. This potential mismatch of supply and demand of type of information is addressed by item \#3. Figure 1 in the Electronic Supplemental Material reveals that this is a salient obstacle: Germany's mean temperature as projected in the median ECHAM5 ensemble member vs. as observed differ by $0.85^{\circ} \mathrm{C}$. Note that given the slope of the warming curve, in above logic this corresponds to a time shift of about 20 years. This difference allows for two main interpretations: (i) ECHAM5 is biased for the temperature average across Germany, or (ii) the present-day observed climate is characterized by a temporary excursion to the high-temperature end as against the mean. Depending on the interpretation, the correction to be applied would work in rather opposite directions (see Table 2). With respect to (ii), such deviations from an average climate are also expected under increased GHG forcing. This effect of climate variability influences the changing return levels in particular when just one (or few) model runs are considered. Table 1 shows, for example, even 
Table 2 A suggestion for a re-interpretation of the previous Section in view of the mismatch of ECHAM5-temperature and observations (see Fig. 1 in the Electronic Supplemental Material)

\begin{tabular}{lcc}
\hline $\begin{array}{l}\text { Temperature discrepancy } \\
\text { interpretation }\end{array}$ & Bias of ECHAM5 & $\begin{array}{c}\text { Excursion of present-day } \\
\text { climate against the mean }\end{array}$ \\
\hline $\begin{array}{l}\text { Downscaling method } \\
\text { Dynamical \& } \\
\text { statistical-dynamical }\end{array}$ & $\begin{array}{c}\text { Time-shift all calculated } \\
\text { impacts by 20 years to }\end{array}$ & $\begin{array}{c}\text { Time-shift calculated } \\
\text { present-day impacts by }\end{array}$ \\
Statistical (STARS) & earlier dates. & 20 years to earlier dates. \\
& As only ECHAM5-trend, & Time-shift calculated future \\
and not the absolute value & impacts by 20 years into \\
& the future. \\
& is utilized, no correction & \\
\hline
\end{tabular}

The correction method depends on both, the downscaling method and the interpretation of the cause of the bias as depicted in that Figure. For a detailed explanation of this Table, see the last Section of the Electronic Supplemental Material

decreasing return levels in the 2041-2070 period compared to both the present day forcing period (1971-2000) and 2011-2040. This suggests that climate is also just one 'realization' of the possible climate conditions under a certain GHG forcing level, and therefore decadal variability can be expected to play a role in our analysis.

Regarding item \#4, the uncertainty on downscaling, we suggest that the model ensemble presented here represents a novel approach to estimate downscaling uncertainty as the ensemble contains two structurally most extreme versions: dynamical versus the particular version of statistical downscaling as used for this article. The latter can be interpreted as the maximum that can be derived from observational data without adding explicit dynamical knowledge. We also address item \#5 for the dynamical approach in deriving an empirical distribution of the deviation from projected and observed impacts. Finally, the finite length of time series (item \#6) has

Fig. 2 Effects of combined uncertainties for the example of dynamical downscaling (CCLM). Damage ratio (in \%o) as a function of return period (in years) for 1971-2000 (95\% confidence intervals). Innermost intervals: Pareto fit uncertainty only. Intermediate intervals: Pareto fit uncertainty convoluted with the uncertainty from nesting CCLM in ECHAM5.

Outermost intervals: Both uncertainties convoluted with damage model uncertainty

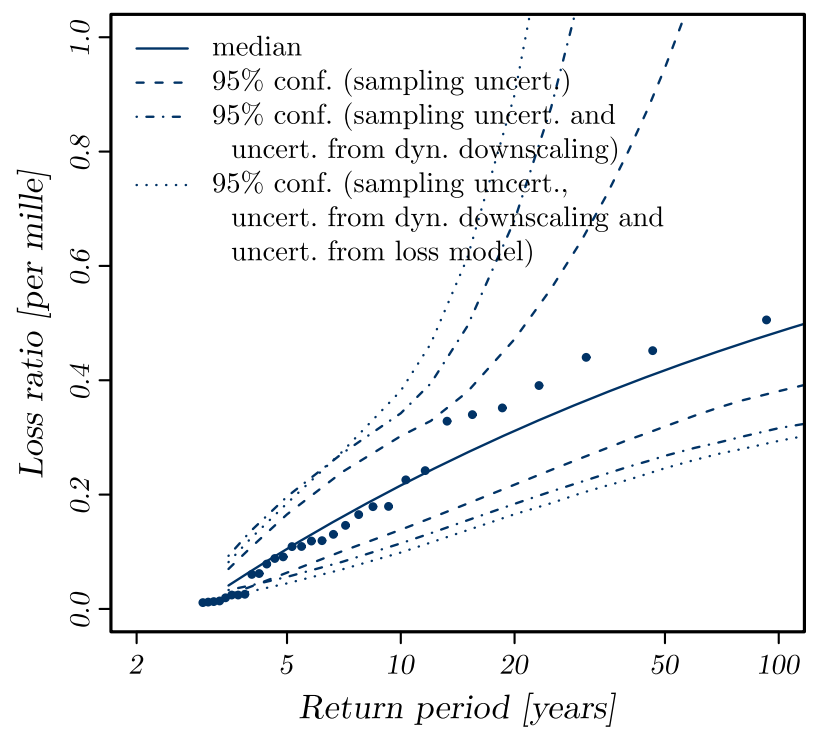


been acknowledged by $95 \%$ profile likelihood confidence intervals when estimating the generalized Pareto distributions from the beginning.

In Fig. 2 we display the uncertainty \#6, a standard measure for Pareto-fits, and successively augment it by the effects of \#5 and \#4 (for the statistical concept and the numerical implementation, see the Electronic Supplemental Material, Section 3). We observe that the inclusion of all three sources of uncertainty augments the confidence intervals by a factor of more than 2 for a return period of 15 years, of less for smaller return periods, and accordingly of more for larger return periods. We conclude that for intermediate return periods, the original Pareto-fit confidence intervals do already provide a good order-of-magnitude estimate for the more inclusive confidence intervals.

\section{Conclusion}

Based on a district-resolved dataset on insured losses of weather extreme events with a coverage of $93 \%$ for Germany, three structurally very different downscaling methodologies combined with translation of wind speeds into loss were applied to global warming (A1B) scenario ensemble simulations. The compilation of all three methods leads to the following results (whereby the period 2071-2100 could only be derived by dynamical and statistical-dynamical downscaling):

1. In response to an A1B scenario, compared to 1971-2000, the downscaling methods indicate an increase of 10 -year return values (i.e. loss ratios per return period) of 6-35\% for 2011-2040, of 20-30\% for 2041-70, and of 40-55\% for 2071-2100, respectively (for the latter period the statistical method does not apply).

2. For larger return periods, increase ratios are found to be on the same order of magnitude.

3. More specifically, compared to 1971-2000, we find a maximum increase of return values of $35,50,58 \%$ for 2011-2040, 2041-2070, and 2071-2100, respectively. For this purpose the maximum is taken across all three downscaling methods (for 2071-2100 omitting the statistical method that however tends to the low-end) and across all return periods as of 10, 25, 50, and 100 years. (Analogously, the minimum increases read as $-35,-19,+40 \%$. Negative increases on shorter time-scales may highlight the influence of climate variability.)

4. All of the above findings are conditional on our highly simplifying assumption that no adaptation measures were anticipated. Preliminary analyzes of our data suggest significant adaptation potential in several regions within Germany.

5. During 2071-2100, windstorms with magnitudes unseen under current climate conditions are identified in these ECHAM5 simulations (see Pinto et al. 2012). Their occurrence could partially be explained by long-term climate variability (see above). However, they might also be an indication that climate change affects significantly the intensity of windstorms over Europe.

6. An uncertainty analysis spelled out for the case of dynamical downscaling suggests that confidence intervals as derived by standard Pareto-fit profilelikelihood methods are a good approximation (within a factor of two for return periods of 15-years or less) for more comprehensive confidence intervals. 
However the factor needed to upscale Pareto fit uncertainty to include multiple uncertainties increases super-linearly with return period.

7. The increase of 10-year return values in the course of this century is generically smaller than the $95 \%$ confidence intervals generated from fitting a Generalized Pareto Distribution. In view of expanding confidence intervals with return period, analogous statements would hold the more so for larger return periods.

8. The project partners from the insurance industry conclude that global- warming induced increases in insured losses under the A1B scenario are generically to be expected, could however be handled within the existing insurance frameworks in Germany.

9. We furthermore suggested options for interpretations how to deal with discrepancies between GCM runs and observation as well as how to extrapolate to the effects of other (than A1B) input scenarios. These options have to be utilized with care and are not to be seen as built on an academic basis of similar quality as our main results. However, they might serve as expert-informed 'bridging technology' for the practitioner as long as solid academic results are missing.

10. All results have passed a twin-test of relevance. The scientific results presented are claimed to be derived according to academic standards. In addition, the priorities set were strongly influenced by the stakeholders involved in the project, the insurance industry. We regard this project a fine example how practitioners can push academic developments, in particular by requesting a combination of structurally most divergent methods in order to minimize surprises in the real-world future development.

Future work will concentrate on a detailed comparison of the results from the three methodologies focusing on regional aspects and on associated uncertainties. Such an analysis will enable the development of detailed climate change impact charts for winter storm risk for insurance purposes.

Acknowledgements The contributions of K. Born, P. Ludwig, M. Donat, T. Pardowitz and B. F. Prahl were partially funded by the GDV-project 'Climate change impacts on the loss situation in the German insurance sector' (2008-2011). We furthermore acknowledge the provision of computing power by the DKRZ (German Climate Computer Centre) to perform the regional climate simulations.

Open Access This article is distributed under the terms of the Creative Commons Attribution License which permits any use, distribution, and reproduction in any medium, provided the original author(s) and the source are credited.

\section{References}

Born K, Ludwig P, Pinto J (2012) Wind gust estimation for Mid-European winter storms: towards a probabilistic view. Tellus A 64:17471. doi:10.3402/tellusa.v64i0.17471, http:/www.tellusa. net/index.php/tellusa/article/view/17471

Coles S (2001) An introduction to statistical modeling of extreme values. Springer Series in Statistics, Springer. http://www.springer.com/statistics/statistical+theory+and+methods/book/ 978-1-85233-459-8

Dee DP, Uppala SM, Simmons AJ, Berrisford P, Poli P, Kobayashi S, Andrae U, Balmaseda MA, Balsamo G, Bauer P, Bechtold P, Beljaars ACM, van de Berg L, Bidlot J, Bormann N, Delsol C, Dragani R, Fuentes M, Geer AJ, Haimberger L, Healy SB, Hersbach H, Hlm EV, Isaksen L, Kllberg P, Khler M, Matricardi M, McNally AP, Monge-Sanz, BM, Morcrette J-J, 
Park B-K, Peubey C, de Rosnay P, Tavolato C, Thpaut J-N, Vitart F (2011) The ERA-interim reanalysis: configuration and performance of the data assimilation system. Q J R Meteorol Soc 137(656):553-597. doi:10.1002/qj.828

Della-Marta, PM, Pinto JG (2009) The statistical uncertainty of changes in winter storms over the North Atlantic and Europe in an ensemble of transient climate simulations. Geophys Res Lett 36(14):L14703. doi:10.1029/2009GL038557

Donat MG, Leckebusch GC, Pinto JG, Ulbrich U (2010) European storminess and associated circulation weather types: future changes deduced from a multi-model ensemble of gcm simulations. Clim Res 42(1):27-43. doi:10.3354/cr00853, http://www.int-res.com/abstracts/cr/v42/n1/ p27-43/

Donat MG, Leckebusch GC, Wild S, Ulbrich U (2011a) Future changes in European winter storm losses and extreme wind speeds inferred from GCM and RCM multi-model simulations. Nat Hazards Earth Syst Sci 11(5):1351-1370. doi:10.5194/nhess-11-1351-2011, http://www.nathazards-earth-syst-sci.net/11/1351/2011/

Donat, MG, Pardowitz T, Leckebusch GC, Ulbrich U, Burghoff O (2011b) High-resolution refinement of a storm loss model and estimation of return periods of loss-intensive storms over Germany. Nat Hazards Earth Syst Sci 11(10):2821-2833. doi:10.5194/nhess-11-2821-2011, http://www.nat-hazards-earth-syst-sci.net/11/2821/2011/

Fuentes U, Heimann D (2000) An improved statisticaldynamical downscaling scheme and its application to the alpine precipitation climatology. Theor Appl Climatol 65:119-135. doi:10.1007/ s007040070038

GDV (2012) Naturgefahrenreport 2012. Naturgefahren und versicherte Schäden in Deutschland eine statistische Übersicht von 1970-2011. Gesamtverband der Deutschen Versicherungswirtschaft. http://www.gdv.de/wp-content/uploads/2012/12/GDV-Naturgefahrenreport-2012.pdf

Gerstengarbe F-W, Werner PC, Österle H, Pardowitz T, Burghoff O (2013) Erratum to: Winter storm- and summer thunderstorm-related loss events with regard to climate change in Germany. Theor Appl Climatol 1-10. doi:10.1007/s00704-013-0878-0

Guha-Sapir D, Vos F, Below S, Ponserre R (2012) Annual disaster statistical review 2011: the numbers and trends. Brussels: CRED. http://reliefweb.int/report/world/annual-disaster-statisticalreview-2011-numbers-and-trends

Haylock MR (2011) European extra-tropical storm damage risk from a multi-model ensemble of dynamically-downscaled global climate models. Nat Hazards Earth Syst Sci 11(10):2847-2857. doi:10.5194/nhess-11-2847-2011, http://www.nat-hazards-earth-syst-sci.net/11/2847/2011/

Jungclaus JH, Keenlyside N, Botzet M, Haak H, Luo J-J, Latif M, Marotzke J, Mikolajewicz U, Roeckner E (2006) Ocean circulation and tropical variability in the coupled model ECHAM5/MPI-OM. J Climate 19(16):3952-3972. doi:10.1175/JCLI3827.1

Kalnay E, Kanamitsu M, Kistler R, Collins W, Deaven D, Gandin L, Iredell M, Saha S, White G, Woollen J, Zhu Y, Leetmaa A, Reynolds R, Chelliah M, Ebisuzaki W, Higgins W, Janowiak J, Mo KC, Ropelewski C, Wang J, Jenne R, Joseph D (1996) The NCEP/NCAR 40year reanalysis project. Bull Am Meteorol Soc 77(3):437-471. doi:10.1175/1520-0477(1996)077< 0437:TNYRP $>2.0 . \mathrm{CO} ; 2$

Klawa M, Ulbrich U (2003) A model for the estimation of storm losses and the identification of severe winter storms in Germany. Nat Hazards Earth Syst Sci 3(6):725-732. doi:10.5194/nhess3-725-2003, http://www.nat-hazards-earth-syst-sci.net/3/725/2003/

Kron W, Steuer M, Löw P, Wirtz A (2012) How to deal properly with a natural catastrophe database analysis of flood losses. Nat Hazards Earth Syst Sci 12(3):535-550. doi:10.5194/nhess-12535-2012, http://www.nat-hazards-earth-syst-sci.net/12/535/2012/

Leckebusch GC, Ulbrich U, Fröhlich L, Pinto JG (2007) Property loss potentials for European midlatitude storms in a changing climate. Geophys Res Lett 34(5):L05703. doi:10.1029/ 2006GL027663

Leckebusch GC, Weimer A, Pinto JG, Reyers M, Speth P (2008) Extreme wind storms over Europe in present and future climate: a cluster analysis approach. Meteorol Z 17(1):67-82. doi:10.1127/0941-2948/2008/0266

Nakicenovic N, Swart R (eds) (2000) Special report on emissions scenarios: a special report of working group III of the intergovernmental panel on climate change. Cambridge University Press, Cambridge

Orlowsky B, Gerstengarbe F-W, Werner PC (2008) A resampling scheme for regional climate simulations and its performance compared to a dynamical RCM. Theor Appl Climatol 92:209223. doi:10.1007/s00704-007-0352-y 
Pinto J, Neuhaus C, Leckebusch G, Reyers M, Kerschgens M (2010) Estimation of wind storm impacts over Western Germany under future climate conditions using a statisticaldynamical downscaling approach. Tellus A 62(2):188-201. doi:10.1111/j.1600-0870.2009.00424.x, http://www.tellusa.net/index.php/tellusa/article/view/1\%5670

Pinto JG, Fröhlich EL, Leckebusch GC, Ulbrich U (2007) Changing european storm loss potentials under modified climate conditions according to ensemble simulations of the ECHAM5/MPIOM1 GCM. Nat Hazards Earth Syst Sci 7(1):165-175. doi:10.5194/nhess-7-165-2007

Pinto JG, Karremann MK, Born K, Della-Marta PM, Klawa M (2012) Loss potentials associated with European windstorms under future climate conditions. Clim Res 54(1):1-20. doi:10.3354/cr01111, http://www.int-res.com/abstracts/cr/v54/n1/p1-20/

Prahl BF, Rybski D, Kropp JP, Burghoff O, Held H (2012) Applying stochastic small-scale damage functions to German winter storms. Geophys Res Lett 39(6):L06806. doi:10.1029/2012GL050961

Rockel B, Will A, Hense A (2008) The regional climate model COSMO-CLM (CCLM). Meteorol Z 17(4):347-348. doi:10.1127/0941-2948/2008/0309

Schiermeier Q (2012) Models hone picture of climate impacts. Nature 482:286. doi:10.1038/482286a

Schwierz C, Köllner-Heck P, Zenklusen Mutter E, Bresch D, Vidale P-L, Wild M, Schär C (2010) Modelling European winter wind storm losses in current and future climate. Climatic Change 101:485-514. doi:10.1007/s10584-009-9712-1

Stern CNH (2007) The Stern review: the economics of climate change. Cambridge University Press, Cambridge

Ulbrich U, Leckebusch G, Pinto J (2009) Extra-tropical cyclones in the present and future climate: a review. Theor Appl Climatol 96(1-2):117-131. doi:10.1007/s00704-008-0083-8

Ulbrich U, Pinto JG, Kupfer H, Leckebusch GC, Spangehl T, Reyers M (2008) Changing Northern hemisphere storm tracks in an ensemble of IPCC climate change simulations. J Clim 21:16691679. doi:10.1175/2007JCLI1992.1

Uppala SM, Kllberg PKW, Simmons AJ, Andrae U, Bechtold VDC, Fiorino M, Gibson JK, Haseler J, Hernandez A, Kelly GA, Li X, Onogi K, Saarinen S, Sokka N, Allan RP, Andersson E, Arpe K, Balmaseda MA, Beljaars ACM, Berg LVD, Bidlot J, Bormann N, Caires S, Chevallier F, Dethof A, Dragosavac M, Fisher M, Fuentes M, Hagemann S, Hlm E, Hoskins BJ, Isaksen L, Janssen PAEM, Jenne R, Mcnally AP, Mahfouf J-F, Morcrette J-J, Rayner NA, Saunders RW, Simon P, Sterl A, Trenberth KE, Untch A, Vasiljevic D, Viterbo P, Woollen J (2005) The ERA40 re-analysis. Q J R Meteorol Soc 131(612):2961-3012. doi:10.1256/qj.04.176 